\section{The COVID-19 Pandemic Management in Psychiatric Patients an Experience from Kigali Rwanda}

\author{
Balthazar Nkundimana $^{1 *}$ and Muhire Emmanuel ${ }^{2}$ \\ ${ }^{1}$ Chongqing Medical University/ The first affiliated Hospital of Chongqing \\ Medical University Department of Psychiatry, China \\ ${ }^{2}$ Ministry of Health Kibagabaga District Hospital, Rwanda
}

\begin{abstract}
The COVID-19 pandemic has affected all domains of human society. The causing virus started in Wuhan /China in December 2019 and sooner later its spread affected the entire world. Countries are still being highly affected with this pandemic numbers of death and confirmed infected new cases are still increasing mostly in western countries, Latin American and most likely few cases in many African countries. In terms of health the COVID-19 pandemic affected not only the physical health as caused by the coronavirus or other diseases but also it has made an effect on mental health. Already suffered mental health patient and new cases were seen to have different challenges as related to pandemic and the mental illness itself. In this case study we aimed to describe the management of mental health patients during the COVID-19 pandemic in Rwanda. We have considered the experience learned in a district Hospital in Kigali. The learned experience is recommended to be used in other communities with similar culture to Rwanda.
\end{abstract}

Keywords: COVID-19; Psychiatric patients; Rwanda

\section{Introduction}

The coronavirus disease known as COVID-19 is a killing virus that is highly contagious. it is caused by a severe acute respiratory coronavirus2 and is spreading from human to human [1]. COVID-19 emerged in Wuhan China in December 2019 and by January 2020 all provinces of China have confirmed COVID-2019 cases [2],

*Corresponding author: Balthazar Nkundimana, Chongqing Medical University/ The first affiliated Hospital of Chongqing Medical University Department of Psychiatry, China, Tel: +250 784083616/725632945; E-mail: nkundbalth@ yahoo.fr

Citation: Nkundimana B, Emmanuel M (2020) The COVID-19 Pandemic Management in Psychiatric Patients an Experience from Kigali Rwanda. J Psychiatry Depress Anxiety 6: 035.

Received: December 22, 2020; Accepted: December 24, 2020; Published: December 31, 2020

Copyright: (c) 2020 Nkundimana B, et al. This is an open-access article distributed under the terms of the Creative Commons Attribution License, which permits unrestricted use, distribution, and reproduction in any medium, provided the original author and source are credited. by march 132020 the WHO proclaimed Wuhan as the center of the pandemic meanwhile it was no longer an epidemic only in China. At the time many European countries and USA reported increasing number of confirmed COVID-19 cases and the number of deaths started increasing in some countries like Italy. And it was believed that Africa and Latin America would be the second infection wave [3]. Nowadays all the world is critically affected by this pandemic, for instance the USA, the Latin America like Brazil, there is an increasing number of confirmed cases [4,5], European countries are straggling with the second wave of COVID-19 infection [6]. The coronavirus pandemic has impacted multiple fields of lives at all level. In highly interconnected and globalized world, the impacted of this pandemic became evident since the outbreak in different countries of the World [7]. In terms of healthcare, the COVID-19 pandemic would not affect only the physical health. Experts show that when there is a an epidemic or pandemic both people who already suffered from psychiatric problems, the general population and people who have never presented symptoms could be at risk of developing mental health symptoms [8]. Causes of mental illness challenges during the pandemic can be due to different reasons for instance when reflecting to COVID-19 scenarios, people around the world has suddenly lost their jobs [9]. Due to this issue a number of people have committed suicide [10]. Further, it was seen that the sudden changes would significantly impact the mental health of psychiatric patients includes reducing their access to psychiatric services. As it was reported in some countries, the shortage of health workers caused the majority of health workers to give the priority to the COVID-19 patients $[11,12]$. Managing mental illness in already diagnosed patients have been a big challenge for mental health professionals, however in some developed societies with good infrastructures different measures such as telepsychiatry consultation, home delivery of medications, psychosocial support, and sometimes rapid test of coronavirus have been put in place in management of mental illness during the pandemic [13].

Rwanda is one of the countries that were affected by the COVID-19 pandemic although the current reported death are still less as compared by other countries (Update-on-COVID-19-19-112020-Eng.Jpg $(720 \times 752)$, n.d.). On the $15^{\text {th }}$ Rwanda has recorded the first case of COVID-19. Soon after, Rwandan government has taken strict measures in containing the spread of the pandemic a lockdown measure has been announced on $20^{\text {th }}$ March many activities were resumed and people were called to stay in their homes unless they might have immergences. (MoH Rwanda). The strict lockdown has taken 40 days. Numbers of COVID-19 confirmed cases have been increasing day by day, currently the total number of infected case counts 5543, with 5137 of the recovered and discharged cases the number of non-recovered cases was 389 on the $19^{\text {th }}$ November 2020 (Update-on-COVID-19-19-11-2020-Eng.Jpg (720×752), n.d.). During the lockdown and after patients were allowed to go the healthcare facilities in all country. Like other patients, psychiatric patients could go and get treatment by following instructions. However, some patients could face challenges in treatment adherence 
since they might live far from the hospital and transport means was limited. Obviously, mental healthcare system in Rwanda is improving. Currently in Rwanda psychiatric patients can get treatment on primary level as many of health centers have one or two trained psychiatrist nurse or psychologist. District hospital and health centers can provide mental health services to both in and out patients. As mentioned previously The sudden occurrence of COVID-19 and the following lockdown in many countries have affected the general population around the world including psychiatric patients [11], in Rwanda, there is no known update on the effected of COVID-19 on mental health either on psychiatric patients or the general population, except a study by [14], that shows genocide survivors with PTSD could not receive the needed treatment during the commemoration period as this one happened during the strict lockdown. Rwanda is also known as a country with a high prevalence of mental health cases of psychiatric illness mostly caused by the consequences of genocide against Tutsis [15].

Rwanda has been recognized as a country that has implemented good measure in containing the pandemic by thinking on all domains that can facilitate to maintain the better life of Rwandan citizens [16]. With this regard, each citizen including psychiatric patient was not left behind in this difficult period of pandemic. In this paper we aimed to describe COVID-19 assistance for psychiatric patients in Rwanda by considering evidence from a District hospital in Kigali the capital city of Rwanda. We referred to Kibagabaga district hospital.

\section{The world mental health day and mental health week in Rwanda}

Each year on $10^{\text {th }}$ October the world celebrates world mental health day. In Rwanda the world mental health day is prepared by mental health professionals who are mainly clinical psychologists, psychiatrists, psychiatric nurses, social workers and other activists from different organizations. The ministry of health through mental health department in Rwanda Biomedical Center (RBC) supports almost all activities as prepared by professionals and activist in mental health. Referring to world mental health day, activities that are commonly done by mental health workers and activists are; radio and TV talks, debates, activities related to campaigns and mobilizations of both populations and resources towards collective actions of awareness, prevention and special attention on mental health illness. This year 2020 because of COVID-19 pandemic many activities were conducted using video conferences. That they were referred to the WHO them which were "Mental health for all: greater investment, greater access".

\section{Mental health week}

There is a good habit in Rwanda for any event that needs a mobilization and sensitization. Similar to this the mental health day can be followed by a mental health week or a mental health week can be prepared later after world mental health day depends on the situation.

\section{How and who participated in mental health week}

The ministry of health/Rwanda biomedical center organizes the reflection training for mental health professional. Each district hospital is called to delegate a mental a staff member who to attend the workshop or symposium. This year, the main purpose of mental health week was to reflect on issues of mental health and mental health patient during the COVID-19 pandemic period. The currently available literature on the covid-19 pandemic was share and discussed by mental health professionals. The experts trained mental health professionals about other issues related to COVID-19. Epilepsy patients were also given a special attention and a special epilepsy week was prepared.

\section{COVID-19 and psychiatric patients in Rwanda}

Psychiatric patients received the need treatment during the lockdown until today except minor challenges as the pandemic occurred unpredictably. Currently there is no known research about potential challenges regarding psychiatric illness and COVID-19 pandemic in Rwanda. However, health authorities assumed that psychiatric patients and neuropsychiatric patients and their caregivers may get confused about symptoms of COVID-19 and other mental health or neuropsychiatric disorders' symptoms. Therefore, as solution for this matter, mental health workers were called to explain difference in symptoms especially the epilepsy symptoms and corona virus symptoms. Differences in symptoms were explained in local language (Kinyarwanda) Mental health workers were requested to make it available for all patients and caregivers. It was then posted on the dashboard of mental health department at the Hospital. Details on the explanations are seen on the (Figure 1).

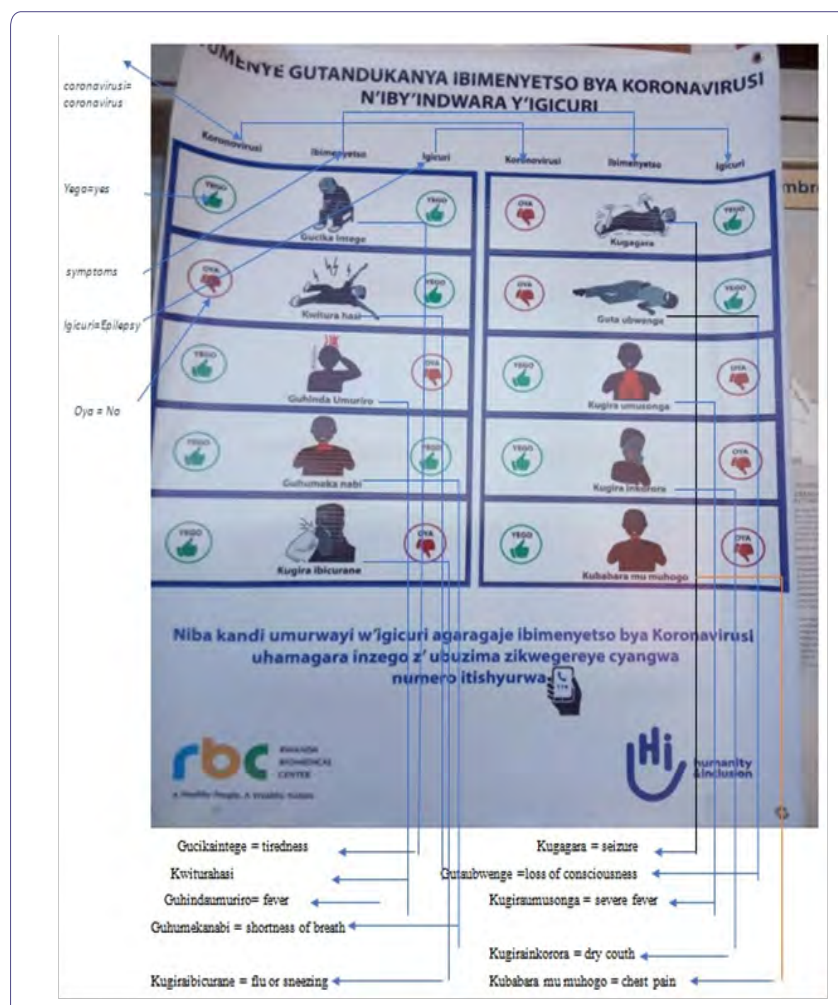

Figure 1: Difference between epilepsy symptoms and Coronavirus symptoms.

\section{Health instructions about and acceptance in psychiatric patients}

Generally, psychiatric patients in our patients department were seen to follow instructions of sanitation and other instructions as 
recommended by the ministry of health in Rwanda. Generally, instructions are social distancing when in Public place, wearing a face mask, frequent hand washing, and avoid non-essential movements. Psychiatric patients as well as their caregivers were seen to be aware of all of these instructions. The need was only to reeducate them and caregivers on the proper use of the instruction as the pandemic is still spreading.

\section{The proper wearing of a face mask and availability in psy- chiatric patient}

The use of face mask was seen successful and helpful in prevention of spread of not only COVID-19 but also other respiratory infectious diseases [17]. It is crucial to wear the face mask during the epidemic period every time in the public place. people should wear the face mask and wear it properly $[18,19]$, wearing a face mask should be the commitment for each and everyone in fighting the spread of pandemic it should not be an obligation from the authorities and people have to accept it in avoiding punishments [18]. Patients were educated the role of wearing the facemask and why they should take it as their responsibility. The good standard qualities of the mask, the time limit of use of a facemask a day, the proper hygiene of a facemask were explained to patients and caregivers. In further helping of psychiatric patients the psychiatric department has provided facemask for patients and their caregivers.

\section{Proper hand wash}

Like the use of facemask, the habit of frequent hand wash was seen helpful in preventing the spread of virus including the coronavirus. The hand hygiene could be done using recommended soap, potable water, and recommend hand sanitizers [20]. Rwanda has made available needed hygiene products in every frequented public place, in further fighting the virus hand sanitizers are available in almost all shops on reasonable price in Rwanda, COVID-19 fighting products are also allowed to sell on street. The department of mental health has arranged soaps for each patient and caregiver and this initiative is supposed to be sustained as a number of psychiatric patients would have challenges in paying some of hand hygiene products.

\section{Avoid unnecessary trips or movements}

The movement restriction and self-isolation and lockdown are one of key decision in the prevention of the spread of the coronavirus pandemic. Self-isolation in helpful even when there is no strict generalized lockdown $[21,22]$. Therefore, people are recommended to stay home whenever they don't have an immergence. In case they are in public place, people must avoid the otherwise used habits such as handshakes, other cultural salutations habits like hugging each other. They must maintain distance at least one meter in between each individual. Similar to general public psychiatric patients were getting explanations and importance of these instructions in protecting themselves as well as the general population. In addition to all assistance that patients and their caregivers received, caregivers were given a hotline number to call in case they may detect some COVID-19 related symptoms. or if they may need further assistance related to COVID-19.

\section{Conclusion}

The occurrence of an epidemic or pandemic can affect mental health in the general population. This may become more severe in people already suffering from a mental health illness. The courage of increasing management measures for mental health patients is highly recommended until the end of the pandemic. The experience learned from Rwanda would help as an example especially in countries with similar culture as Rwanda. As the pandemic is still spreading, we recommend mental health professional to keep informing mental health patients about their contribution in the fight of the pandemic by protecting themselves as well as the general population. It also important to note that in Rwanda the epilepsy is treated in mental health department of each district hospital. Therefore, considering it as a mental health problem is quite common in general public and sometimes in health professionals. Furthermore, the epilepsy related stigma and other psychosocial issues need to be investigated in Rwanda. As Rwanda is growing in healthcare there is a need to keep strengthening research in healthcare in general and mental health in particular.

\section{References}

1. Mayoclinic (2020) Coronavirus disease 2019 (COVID-19). Mayoclinic, Scottsdale, USA.

2. Xiaoming X, Ming A, Su H, Wo W, Jianmei C, et al. (2020) The psychological status of 8817 hospital workers during COVID-19 Epidemic: A cross-sectional study in Chongqing. Journal of Affective Disorders 276: 555-561.

3. Lancet T (2020) COVID-19: Learning from experience. Lancet 395: 1011.

4. Omer SB, Malani P, Rio C (2020) The COVID-19 pandemic in the US: A clinical update. JAMA 323: 1767-1768.

5. Ribeiro H, Lima VM, Waldman EA (2020) In the COVID-19 pandemic in Brazil, do brown lives matter? The Lancet Global Health 8: 976-977.

6. Cacciapaglia G, Cot C, Sannino F (2020) Second wave COVID-19 pandemics in Europe: A temporal playbook. Scientific Reports 10: 1-8.

7. McKibbin WJ, Fernando R (2020) The global macroeconomic impacts of COVID-19: Seven scenarios. Centre for Applied Macroeconomic Analysis, Australia.

8. Rajkumar RP (2020) COVID-19 and mental health: A review of the existing literature. Asian Journal of Psychiatry 52: 102066.

9. Cacciapaglia G, Cot C, Sannino F (2020) Second wave COVID-19 pandemics in Europe: A temporal playbook. Scientific Reports 10: 1-8.

10. Sher L (2020) COVID-19, anxiety, sleep disturbances and suicide. Sleep Med 70: 124 .

11. Montemurro N (2020) The emotional impact of COVID-19: From medical staff to common people. Brain, Behavior, and Immunity 87: 23-24.

12. Kim S-W, Su K-P (2020) Using psychoneuroimmunity against COVID-19. Brain, Behavior, and Immunity 87: 4-5.

13. Hao F, Tan W, Jiang L, Zhang L, Zhao X, et al. (2020). Do psychiatric patients experience more psychiatric symptoms during COVID-19 pandemic and lockdown? A case-control study with service and research implications for immunopsychiatry. Brain, Behavior, and Immunity 87: 100-106.

14. Ngamije J, Yadufashije C (2020) COVID-19 pandemic against mental health services for genocide survivors during commemoration week in Rwanda. Heliyon 6: 05229.

15. Schaal S, Weierstall R, Dusingizemungu J-P, Elbert T (2012) Mental health 15 years after the killings in Rwanda: Imprisoned perpetrators of the genocide against the Tutsi versus a community sample of survivors. Journal of Traumatic Stress 25: 446-453. 
Citation: Nkundimana B, Emmanuel M (2020) The COVID-19 Pandemic Management in Psychiatric Patients an Experience from Kigali Rwanda. J Psychiatry Depress Anxiety 6: 035 .

- Page 4 of 5 -

16. Bower J, Apell D, Twum A (2020) Rwanda's response to COVID-19 and future challenges. International Growth Centre, London, UK.

17. Swain ID (2020) Why the mask? The effectiveness of face masks in preventing the spread of respiratory infections such as COVID-19 - a home testing protocol. Journal of Medical Engineering \& Technology 44: 334 337.

18. Cheng VCC, Wong SC, Chuang VW, Sridhar S, Hung I, et al. (2020) The role of community-wide wearing of face mask for control of coronavirus disease 2019 (COVID-19) epidemic due to SARS-CoV-2. The Journal of Infection 81: 107-114.

19. Matuschek C, Moll F, Fangerau H, Fischer JC, Zänker K, et al. (2020) Face masks: Benefits and risks during the COVID-19 crisis. European Journal of Medical Research 25: 32
20. Hillier MD (2020) Using effective hand hygiene practice to prevent and control infection. Nursing Standard 35: 45-50.

21. Matias T, Dominski FH, Marks DF (2020) Human needs in COVID-19 isolation. Journal of Health Psychology 25: 871-882.

22. Sjödin H, Wilder-Smith A, Osman S, Farooq Z, Rocklöv J (2020) Only strict quarantine measures can curb the coronavirus disease (COVID-19) outbreak in Italy, 2020. Euro Surveillance: Bulletin Europeen Sur Les Maladies Transmissibles $=$ European Communicable Disease Bulletin 25: 2000280. 


\section{di \\ нramb}

Advances In Industrial Biotechnology | ISSN: 2639-5665

Advances In Microbiology Research | ISSN: 2689-694X

Archives Of Surgery And Surgical Education | ISSN: 2689-3126

Archives Of Urology

Archives Of Zoological Studies | ISSN: 2640-7779

Current Trends Medical And Biological Engineering

International Journal Of Case Reports And Therapeutic Studies | ISSN: 2689-310X

Journal Of Addiction \& Addictive Disorders | ISSN: 2578-7276

Journal Of Agronomy \& Agricultural Science | ISSN: 2689-8292

Journal Of AIDS Clinical Research \& STDs | ISSN: 2572-7370

Journal Of Alcoholism Drug Abuse \& Substance Dependence | ISSN: 2572-9594

Journal Of Allergy Disorders \& Therapy | ISSN: 2470-749X

Journal Of Alternative Complementary \& Integrative Medicine | ISSN: 2470-7562

Journal Of Alzheimers \& Neurodegenerative Diseases | ISSN: 2572-9608

Journal Of Anesthesia \& Clinical Care | ISSN: 2378-8879

Journal Of Angiology \& Vascular Surgery | ISSN: 2572-7397

Journal Of Animal Research \& Veterinary Science | ISSN: 2639-3751

Journal Of Aquaculture \& Fisheries | ISSN: 2576-5523

Journal Of Atmospheric \& Earth Sciences | ISSN: 2689-8780

Journal Of Biotech Research \& Biochemistry

Journal Of Brain \& Neuroscience Research

Journal Of Cancer Biology \& Treatment | ISSN: 2470-7546

Journal Of Cardiology Study \& Research | ISSN: 2640-768X

Journal Of Cell Biology \& Cell Metabolism | ISSN: 2381-1943

Journal Of Clinical Dermatology \& Therapy | ISSN: 2378-8771

Journal Of Clinical Immunology \& Immunotherapy | ISSN: 2378-8844

Journal Of Clinical Studies \& Medical Case Reports | ISSN: 2378-8801

Journal Of Community Medicine \& Public Health Care | ISSN: 2381-1978

Journal Of Cytology \& Tissue Biology | ISSN: 2378-9107

Journal Of Dairy Research \& Technology | ISSN: 2688-9315

Journal Of Dentistry Oral Health \& Cosmesis | ISSN: 2473-6783

Journal Of Diabetes \& Metabolic Disorders | ISSN: 2381-201X

Journal Of Emergency Medicine Trauma \& Surgical Care | ISSN: 2378-8798

Journal Of Environmental Science Current Research | ISSN: 2643-5020

Journal Of Food Science \& Nutrition | ISSN: 2470-1076

Journal Of Forensic Legal \& Investigative Sciences | ISSN: 2473-733X

Journal Of Gastroenterology \& Hepatology Research | ISSN: 2574-2566
Journal Of Genetics \& Genomic Sciences | ISSN: 2574-2485

Journal Of Gerontology \& Geriatric Medicine | ISSN: 2381-8662

Journal Of Hematology Blood Transfusion \& Disorders | ISSN: 2572-2999

Journal Of Hospice \& Palliative Medical Care

Journal Of Human Endocrinology | ISSN: 2572-9640

Journal Of Infectious \& Non Infectious Diseases | ISSN: 2381-8654

Journal Of Internal Medicine \& Primary Healthcare | ISSN: 2574-2493

Journal Of Light \& Laser Current Trends

Journal Of Medicine Study \& Research | ISSN: 2639-5657

Journal Of Modern Chemical Sciences

Journal Of Nanotechnology Nanomedicine \& Nanobiotechnology | ISSN: 2381-2044 Journal Of Neonatology \& Clinical Pediatrics | ISSN: 2378-878X

Journal Of Nephrology \& Renal Therapy | ISSN: 2473-7313

Journal Of Non Invasive Vascular Investigation | ISSN: 2572-7400

Journal Of Nuclear Medicine Radiology \& Radiation Therapy | ISSN: 2572-7419

Journal Of Obesity \& Weight Loss | ISSN: 2473-7372

Journal Of Ophthalmology \& Clinical Research | ISSN: 2378-8887

Journal Of Orthopedic Research \& Physiotherapy | ISSN: 2381-2052

Journal Of Otolaryngology Head \& Neck Surgery | ISSN: 2573-010X

Journal Of Pathology Clinical \& Medical Research

Journal Of Pharmacology Pharmaceutics \& Pharmacovigilance | ISSN: 2639-5649

Journal Of Physical Medicine Rehabilitation \& Disabilities | ISSN: 2381-8670

Journal Of Plant Science Current Research | ISSN: 2639-3743

Journal Of Practical \& Professional Nursing | ISSN: 2639-5681

Journal Of Protein Research \& Bioinformatics

Journal Of Psychiatry Depression \& Anxiety | ISSN: 2573-0150

Journal Of Pulmonary Medicine \& Respiratory Research | ISSN: 2573-0177

Journal Of Reproductive Medicine Gynaecology \& Obstetrics | ISSN: 2574-2574

Journal Of Stem Cells Research Development \& Therapy | ISSN: 2381-2060

Journal Of Surgery Current Trends \& Innovations | ISSN: 2578-7284

Journal Of Toxicology Current Research | ISSN: 2639-3735

Journal Of Translational Science And Research

Journal Of Vaccines Research \& Vaccination | ISSN: 2573-0193

Journal Of Virology \& Antivirals

Sports Medicine And Injury Care Journal | ISSN: 2689-8829

Trends In Anatomy \& Physiology | ISSN: 2640-7752

Submit Your Manuscript: https://www.heraldopenaccess.us/submit-manuscript 